Pesquisa com Professores de Química do Ensino Médio de Uberaba / MG: Laboratórios das Escolas e Capacitação dos Professores

\author{
Faria, R. R.;* Souza, I. A. B.; Dias, R. F.; Dias, R. F. C; Franca, E. F.; Oliveira, \\ G. S.; Oliveira, L. R.; Paula, L. F.; Segatto, M. S.; Júnior, O. A.; Neto, L. R. S.
}

Rev. Virtual Quim., 2019, 11 (4), 1225-1238. Data de publicação na Web: 21 de agosto de 2019

http://rvq.sbq.org.br

\title{
Research with Chemistry Teachers from the High Schools of Uberaba/MG: School Laboratories and Teacher Training
}

Abstract: The reality of public schools in the city of Uberaba, state of Minas Gerais, elucidated in this research analyzed the ability of chemistry teachers to teach their classes, as well as the occurrence of experimental classes, infrastructure and availability of materials in laboratories. The proposal addresses the educational and structural context of teaching chemistry in schools, with information collected through questionnaires with chemistry teachers from 19 different state schools with secondary education. The study examined the teacher profile, the knowledge of educational guidelines, the presence and infrastructure of the laboratories, the frequency of practical classes in chemistry, the availability of materials for the classes and the existence of a laboratory technician. The results revealed the lack of structure, materials and professionals in the chemistry laboratories, besides the lack of training of the teachers in experimental activities; needing improvement of the graduates to improve their pedagogical methodologies.

Keywords: Chemistry; research; teachers; teaching; laboratory.

\section{Resumo}

A realidade das escolas públicas da cidade de Uberaba, no estado de Minas Gerais, elucidada nesta pesquisa analisou a capacidade dos professores de química em ministrar suas aulas, além da ocorrência de aulas experimentais, infraestrutura e disponibilidade de materiais nos laboratórios. A proposta aborda o contexto educacional e estrutural do ensino de química nas escolas, com coleta de informações realizada através de questionários com os professores de química de 19 diferentes escolas estaduais com ensino médio. O estudo examinou o perfil do professor, o conhecimento das diretrizes educacionais, a presença e infraestrutura dos laboratórios, a frequência das aulas práticas de química, a disponibilidade de materiais para as aulas e a existência de técnico laboratorial. Os resultados revelaram a falta de estrutura, materiais e profissionais nos laboratórios de química, além da falta de capacitação dos professores em atividades experimentais; havendo a necessidade de aperfeiçoamento dos licenciados para melhorar suas metodologias pedagógicas.

Palavras-chave: Química; pesquisa; professores; ensino; laboratório.

\footnotetext{
* Universidade Federal de Uberlândia, Instituto de Química, Campus Santa Mônica, CEP 38400-902, Uberlândia-MG, Brasil.

M robertoribeiro90@gmail.com DOI: $10.21577 / 1984-6835.20190084$
} 


\title{
Pesquisa com Professores de Química do Ensino Médio de Uberaba / MG: Laboratórios das Escolas e Capacitação dos Professores
}

\author{
Roberto R. Faria, * Izadora A. B. de Souza, Renieidy F. C. Dias, Eduardo F. \\ Franca, Guedmiller S. Oliveira, Lhigia R. Oliveira, Leonardo F. Paula, \\ Monica S. Segatto, Odonirio A. Júnior, Lourival R. S. Neto \\ Universidade Federal de Uberlândia, Instituto de Química, Campus Santa Mônica, CEP 38400-902, Uberlândia-MG, \\ Brasil. \\ * robertoribeiro90@gmail.com
}

Recebido em 28 de janeiro de 2019. Aceito para publicação em 3 de junho de 2019

1. Introdução

2. Pesquisa nas Escolas

\section{Respostas dos Professores}

3.1. Formação acadêmica

3.2. Aptidão dos Professores

3.3. Laboratórios das Escolas

3.4. Aulas experimentais

\section{Considerações Finais}

\section{Introdução}

A educação no Brasil tem sido bastante questionada e se torna alvo de discussões, pois deve atender a população de forma homogênea e conter os recursos mínimos necessários para garantir um ensino de qualidade, este fato vem de acordo com a Constituição Federal, principalmente no que tange o Art. 205 "A educação é direito de todos e dever do estado e da família". ${ }^{1}$

Segundo Demerval Saviani "o processo educativo é a passagem da desigualdade à igualdade", 2 assim, o profissional necessita desenvolver suas competências de forma crítica, em níveis mais complexos de estudos, para romper a barreira da desigualdade social, intelectual e informativa. Nestas competências, o nível cognitivo, cultural, psicomotor e sócio afetivo corresponde às referências básicas da epistemologia genética de Jean Piaget. $^{3}$

O estudo de química é essencial na formação de um jovem, o Ministério da Educação propõe que "os conhecimentos difundidos no ensino de química permitem a construção de uma visão de mundo mais articulada, menos engessada e fragmentada, contribuindo para que o indivíduo se olhe como participante de um processo onde o mundo está em constante transformação", 
desta forma as legislações LDBEN, ${ }^{4}$ DCNEM $^{5} \mathrm{e}$ o Fundo de Desenvolvimento da Educação Básica (FUNDEB) ${ }^{6}$ devem permitir que o país aumentasse os recursos destinados à Educação.

O Conselho Nacional de Educação (CNE) propõe condições para avançar as políticas educacionais brasileiras com objetivo de melhoria da qualidade do ensino, a formação e valorização dos profissionais da educação, além da inclusão social. Porém, para alcançar o pleno desenvolvimento da educação, o Brasil precisa investir na ampliação de sua capacidade tecnológica, como laboratórios de ciências da natureza e a formação dos profissionais para ministrar aulas com qualidade. $^{7}$

A escola representa um papel muito importante na formação do cidadão, em especial no ensino médio por se tratar da última etapa da Educação Básica, uma vez que o ensino nas escolas vai além da formação para o mercado de trabalho, este atinge o processo de construção da cidadania, permitindo que a população desenvolva a autocrítica e se rompa de ideologias alienadas, por isso, faz-se necessário oferecer aos jovens novas perspectivas com um ensino mais dinâmico e interdisciplinar para que possam expandir seus horizontes e dotá-los de autonomia intelectual, assegurando-lhes o processo epistemológico com acesso ao conhecimento e à produção coletiva de novos conhecimentos, a educação consiste, portanto, em uma chave para o exercício de direitos e deveres sociais. ${ }^{8}$

O ensino médio passa por transformações a fim de melhorar a organização e o funcionamento laboral, e consequentemente a qualidade de ensino. Desta forma, propostas de mudanças têm sido feitas na forma de leis, decretos e de portarias ministeriais que visam, desde a inclusão de novas disciplinas e conteúdos, até a alteração da forma de financiamento das instituições de ensino. Dois exemplos dessas alterações legislativas podem ser a criação do Fundo de Educação Básica (FUNDEB) e a ampliação da obrigatoriedade de escolarização, resultante da Emenda Constitucional no 59, de novembro de 2009. ${ }^{6}$ A LDB e a DCNEM definem que o ensino médio consiste numa preparação para vincular a educação como a preparação para o trabalho e exercício da cidadania, aproximando o ensino da realidade da população. ${ }^{7}$

A nova reforma do ensino médio, instituída no Brasil, sob medida provisória em 22 de setembro de 2016, apresenta uma Base Nacional Comum Curricular (BNCC) que flexibiliza a grade curricular, esta base dá ao aluno o direito a escolher a área de conhecimento para estudar. A BNCC dá foco à formação do aluno como cidadão preparado para o mercado de trabalho, com um ensino contextualizado focado em ensinar matérias como português e matemática, o que negligencia a formação do estudante, que com o pouco destaque aos campos humanos e científicos deixa de estimular o estudante a pensar criticamente. ${ }^{9}$

O presente trabalho visa analisar a situação da capacitação profissional dos professores de química nas escolas públicas de ensino médio da cidade de Uberaba, em Minas Gerais, tais como seus conhecimentos das leis e diretrizes, aptidões para lecionar, capacitações, domínios de conteúdo e contextualização durante as aulas, além da utilização de experimentos, analisando a existência e viabilidade dos laboratórios, bem como a frequência de suas utilizações.

\section{Pesquisa nas Escolas}

A pesquisa se iniciou pela visita a todas as escolas públicas estaduais de ensino médio da cidade de Uberaba, onde 19 escolas permitiram a realização dos questionários contendo 19 perguntas (Tabelas 1 a 19), sendo um professor de química entrevistado para cada escola.

A pesquisa considerou a realidade atual das escolas e dos professores que ministram a disciplina de química na cidade, bem como as aulas dentro de sala e em laboratório, assim, a investigação tornou-se necessária para correlacionar as lições teóricas instruídas com 
a experimentação da química, bem como as condições reais e a infra-estrutura existente nos laboratórios. A investigação sobre o universo da escola ocorreu sem ideias préconcebidas, buscando observar a relação entre química e o cotidiano dentro e fora do ambiente escolar.

O município de Uberaba se localiza no interior do estado de Minas Gerais, na região do Triângulo Mineiro, sua população em julho de 2017, segundo a estimativa do Instituto Brasileiro de Geografia e Estatística (IBGE), era de 328.272 habitantes e corresponde ao oitavo município mais populoso do estado. Contudo, as instituições educacionais analisadas correspondem a $76,0 \%$ das 25 escolas estaduais urbanas da cidade com ensino médio.

A pesquisa aconteceu sob a forma de reuniões, com questões diretas e sistemáticas sobre a estrutura física dos laboratórios da escola e treinamento prático dos professores. As questões, apresentadas a seguir, juntamente com os resultados, foram elaboradas para uma avaliação ampla, com foco no objetivo principal que consiste em identificar a capacitação dos professores e a realização de atividades experimentais de Química no ensino médio público estadual na cidade de Uberaba/MG.
As entrevistas ocorreram no tempo de aproximadamente 30 minutos com cada professor, aplicados em horários reservados com o conselho escolar e as respostas foram agrupadas em planilha eletrônica para análise qualitativa e quantitativa.

\section{Respostas dos Professores}

\subsection{Formação acadêmica}

A formação na área de atuação de um professor é primordial, visto que somente na graduação é possível conhecer e vivenciar todo o conteúdo disciplinar a ser ministrado aos alunos. Inclusive o Ministério da Educação propõe que "os conhecimentos difundidos no ensino de química permitem a construção de uma visão de mundo mais articulada, menos engessada, menos fragmentada, contribuindo para que $o$ indivíduo se olhe como participante de um processo onde o mundo está em constante transformação". ${ }^{5}$ Desta forma, a Tabela 1 representa a primeira pergunta feita para os professores, a respeito de possuírem ou não graduação na área de química, na qual estes ministram suas aulas.

Tabela 1. Número de profissionais com graduação em química

\begin{tabular}{ccc}
\hline \multicolumn{3}{c}{ Possui graduação em Química? } \\
\hline Sim & Não & Sou Graduando \\
\hline 19 & 0 & 0 \\
$100 \%$ & $0 \%$ & $0 \%$ \\
\hline
\end{tabular}

A Tabela 1 mostrou que todos os professores são formados na área, este fato pode ser justificado pela existência de 2 cursos de licenciatura em química presentes na cidade. De acordo com a Lei de Diretrizes e Bases da Educação Nacional, o professor somente pode lecionar caso tenha graduação na área. ${ }^{10}$ As diretrizes das Ciências da Natureza são diversas, todas com suas devidas aplicações e importâncias, entre elas está a licenciatura em química, a qual é exigida como uma das metas que o Projeto de Lei cria para o novo PNE a serem alcançadas pelo país até 2020. ${ }^{11}$

As metas estabelecidas no PNE exigem que todos os professores da educação básica possuam formação especifica de nível 
superior e licenciatura em sua área de atuação, garantido em parceria entre União, Estados e o Distrito Federal. ${ }^{12} \mathrm{O}$ conhecimento vai além do "saber científico", e torna importante a abordagem psicopedagógica oferecida por profissionais licenciados. Desta forma, a Tabela 2 aponta qual o tipo de graduação que os professores possuem na área (Licenciatura ou Bacharelado).

Tabela 2. Número de Licenciados ou Bacharelados em química

\begin{tabular}{cc}
\hline \multicolumn{2}{c}{ A graduação em Química refere-se a: } \\
\hline Licenciatura & Bacharelado \\
\hline 19 & 0 \\
$100 \%$ & $0 \%$ \\
\hline
\end{tabular}

A Tabela 2 mostrou que os professores formados na área de química da cidade de Uberaba - MG possuem licenciatura em química, o que demonstra uma preocupação não somente com a formação do professor, mas também na reprodução de conteúdo. A licenciatura em química além de possibilitar ao profissional o direito de exercer o magistério, também capacita o profissional à didática em sala de aula. Essa didática vai além da interação pedagógica entre aluno e professor, tratando de abordagens adequadas e interações psicopedagógica, é essencial na construção do conhecimento.
Existe também, o curso superior em ciências naturais que qualifica o graduado em licenciatura. Há alguns anos, era comum que professores tivessem esse tipo de formação. Porém, com o desenvolvimento das ciências, novas propostas foram difundidas para que $o$ professor possua conhecimento específico na área de atuação, o que influencia diretamente no desempenho em sala de aula. A Tabela 3 trata do questionamento sobre a contextualização do conteúdo nas aulas de química, ou seja, de acordo com a auto avaliação do professor, qual o domínio em conseguir relacionar conteúdo e contexto nas aulas para um melhor aprendizado dos alunos.

Tabela 3. Contextualização do conteúdo nas aulas de química

\begin{tabular}{ccc}
\hline \multicolumn{3}{c}{ Consegue contextualizar o conteúdo nas aulas de Química? } \\
\hline Sim & Não & Às Vezes \\
\hline 14 & 2 & 3 \\
$73,68 \%$ & $10,52 \%$ & $15,78 \%$ \\
\hline
\end{tabular}

A Tabela acima indica que $73,68 \%$ dos professores de química entrevistados conseguem contextualizar o conteúdo ministrado em suas aulas, $10,52 \%$ não conseguem e $15,78 \%$ ás vezes conseguem, como todos os profissionais têm formação em sua área de atuação, este resultado pode ser explicado pelo constante estresse sofrido pelos professores brasileiros, visto que a docência no Brasil é considerada uma das atividades profissionais mais estressantes. São inúmeras as condições adversas da docência, e é exigido muito dos professores, o que contribui para altos índices de estresse ocupacional. ${ }^{13}$

Esse estresse enfrentado pelos professores pode ser chamado, na psicologia, de Burnout, uma síndrome que tem como sintoma a 
sensação de esgotamento físico e emocional. O professor perde o prazer em sua vida, levando a um sentimento de descontentamento pessoal, o que faz com que o trabalho perca o sentido e passa a ser um sacrifício. ${ }^{13}$

A graduação com licenciatura em química é muito importante pois permite o domínio de metodologias de ensino não tradicionais, que ensina o uso de técnicas não contextualizadas para motivar os alunos. Além da formação dos professores, faz-se necessário o incentivo no ambiente de trabalho para motivar os alunos ao conteúdo, portanto existe a importância da busca de técnicas para motivar a atenção dos alunos, um exemplo simples de metodologia não contextualizada seria o professor de química ensinar aos alunos as propriedades periódicas de cada elemento e não força-los a decorar a tabela periódica.

A escola deve priorizar, em sua metodologia, processos capazes de gerar sujeitos inventivos, participativos, cooperativos, preparados para diversificadas áreas, inserções sociais, políticas, culturais, profissionais e, ao mesmo tempo, capazes de intervir e gerenciar as formas de produção e de vida. A lei de diretrizes e bases LDB 9.394/96, no artigo $28^{\circ}$ cobra que os sistemas de ensino promovam adaptações necessárias de acordo com a realidade vivida pelos alunos, levando em conta o cotidiano e a realidade de cada região. ${ }^{10} \mathrm{~A}$ Tabela 4 mostra a quantidade de professores de química que além da graduação, se capacitaram com algum curso de pós-graduação em sua área especifica, Lato ou Stricto Sensu.

Tabela 4. Quantidade de profissionais com Pós-Graduação em química

\begin{tabular}{ccc}
\hline \multicolumn{3}{c}{ Possui pós-graduação em Química? } \\
\hline Sim & Não & Sou Pós-Graduando \\
\hline 11 & 8 & 0 \\
$57,89 \%$ & $42,11 \%$ & $0 \%$
\end{tabular}

A pesquisa realizada mostra $57,89 \%$ dos professores com pós-graduação Lato Sensu em química e 42,11 \% não considera importante ou não tiveram condições de se capacitarem tanto em Lato Sensu quanto Stricto Sensu. Dos entrevistados sem pósgraduação, 5 confirmaram o interesse em se qualificarem, porém não tinham no momento tempo e disposição, devido à sobrecarga de aulas no ensino público.

Do ponto de vista qualitativo, uma melhora da profissionalização do professor deve ir além da graduação, sendo que especializações que fomentam a área de formação do docente devem ser incentivadas continuamente. (MELLO, 2000). O profissional da educação necessita do conhecimento suficiente para modificar o sistema escolar, levando em consideração o aluno no seu contexto de aprendizagem. ${ }^{14}$

O projeto de lei criado para estabelecer as metas do PNE para a melhoria na educação brasileira estabelece, por exemplo, o incentivo à formação continuada em sua área de atuação. ${ }^{11}$ Assim, ao considerar os dados da pesquisa, resta a preocupação sobre as especializações para o magistério em nível básico, visto que sua qualidade não é demandada e a ascensão dos títulos acadêmicos se dissipam principalmente por interesses financeiros e não pelo ensino de qualidade. Embora os professores sejam licenciados e a maioria possua pós-graduação, a Tabela 5 investiga se os mesmos se consideram aptos a lecionar. 


\subsection{Aptidão dos professores}

A Tabela 5 apresenta todos os licenciados se considerando aptos para o ensino da disciplina de química, o que não condiz com a Tabela 3, indicando que $73,68 \%$ dos professores entrevistados que conseguem contextualizar suas aulas, o fato de se considerar apto implica em saber contextualizar suas aulas, portanto estes professores entrevistados evidenciam contradição em suas afirmações.

Tabela 5. Professores autodeclarados aptos para ensinar a disciplina de química

\begin{tabular}{cc}
\hline \multicolumn{2}{c}{ Você se considera apto para ensinar a disciplina de Química? } \\
\hline Sim & Não \\
\hline 19 & 0 \\
$100 \%$ & $0 \%$ \\
\hline
\end{tabular}

Essa análise implica no domínio da ciência, condições de trabalho adequadas, materiais disponíveis e carga horária suficiente. Todavia, para ser apto deve-se haver planejamento, ter conhecimento do conteúdo e didática. Afinal, estar à frente no processo de formação de conhecimento é de enorme responsabilidade, bem como é importante destacar que a área de atuação de um profissional é determinada na graduação. $\mathrm{Na}$ Tabela 6 é apresentado o conhecimento que os professores possuem sobre a Lei de Diretrizes e Bases da Educação Nacional (LDBEN).

Tabela 6. Contato dos professores com a LDBEN

\begin{tabular}{ccc}
\hline \multicolumn{3}{c}{ Já teve algum contato com a Lei de Diretrizes e Bases da Educação Nacional (LDBEN), No } \\
$\mathbf{9 . 3 9 4}$, de 20/12/1996?
\end{tabular}

A Tabela 6 apresenta que maioria dos entrevistados $(68,41 \%)$ com pouco ou nenhum contato com a LDBEN. O conhecimento da LBDEN é imprescindível, ensinada nos cursos de licenciatura, define e regulamenta o sistema educacional brasileiro. ${ }^{10}$ Acredita-se que os cursos de licenciatura não formam professores que se baseiem nessas diretrizes.

A LDBEN busca prover os sistemas educativos em níveis municipal, estadual e federal de instrumentos para a educação dos brasileiros, recebendo uma formação de qualidade correspondente à sua idade e nível de aprendizagem, respeitando suas diferentes condições, e também estabelece uma base nacional comum, que é responsável por orientar a organização, didática e a avaliação das propostas pedagógicas de todas as redes de ensino brasileiras. Além de colocar a educação como alicerce indispensável para o exercício da plena cidadania e acesso aos direitos sociais, econômicos, civis e políticos. ${ }^{10}$ A Tabela 7 menciona o contato dos professores com as Diretrizes Curriculares Nacionais do Ensino Médio (DCNEM). 
Tabela 7. Contato dos professores com DCNEM

\begin{tabular}{ccc}
\hline Já teve algum contato com as Diretrizes Curriculares Nacionais do Ensino Médio (DCNEM), \\
ano 2000?
\end{tabular}

De acordo com a Tabela 7 a maior porcentagem dos entrevistados $(84,21 \%)$ tem conhecimento das Diretrizes Curriculares Nacionais do Ensino Médio, que vincula a educação com o mundo do trabalho e a pratica social na preparação básica e o exercício da cidadania. Nos cursos de licenciatura, ensina-se LDBEN e DCNEM juntos, portanto todos os professores necessitam do conhecimento dessas leis e diretrizes. Além de conhecer a DCNEM faz se necessário utilizar as novas diretrizes em todo o campo educacional, visto que são orientações que normatizam e melhoram o sistema educacional brasileiro. ${ }^{15}$

A Tabela 8 relata a análise realizada a respeito da carga horária teórica das aulas de química nas escolas.

Tabela 8. Opinião dos professores quanto à suficiência da carga horária teórica

\begin{tabular}{cc}
\hline \multicolumn{2}{c}{ Sob seu ponto de vista, a carga horária teórica é satisfatória? } \\
\hline Sim & Não \\
\hline 4 & 15 \\
$21,05 \%$ & $78,94 \%$ \\
\hline
\end{tabular}

A Tabela 8 mostra que a maior porcentagem dos entrevistados (78,94 \%) considera a carga horária insatisfatória, visto que precisam ministrar todo o conteúdo em tempo escasso, o que afeta a qualidade da aprendizagem dos alunos.

O DCNEM normatiza a carga horária mínima de 2.400 horas, e os professores consideram ser insuficiente lecionar toda a matéria estabelecida nesse tempo. Tal fato influencia diretamente na qualidade das aulas, uma vez que, disciplinas como a química demandam grande atenção, por serem complexas e não estarem presentes no ensino fundamental. ${ }^{5}$

A próxima investigação, tratada na Tabela 9, corresponde à inserção dos professores recém-formados nas escolas.
A Tabela 9 mostra grande parte dos professores atuando por mais de 5 anos, o que representa 78,94\% dos entrevistados, sendo apenas $15,78 \%$ com 1 a 3 anos de docência e nenhum professor com menos de 1 ano nas escolas. Logo, evidencia-se que professores recém-formados não são inseridos nas escolas, devido ao pouco número de vagas oferecidas para o cargo de professor na região. $^{16}$

A maioria esmagadora que leciona a mais de 5 anos deveria conhecer as DCNEM e LDBEN, e muitos ainda possuem dificuldade em contextualizar suas aulas, como mostrado nas tabelas anteriores. Indica-se ainda a falta de oportunidade profissional para os recémformados, pois estes podem estar aptos para lecionar, assim também atualizados quanto às leis, diretrizes e metodologias pedagógicas. Por conseguinte, a Tabela 10 relata a opinião 
dos professores quanto a dificuldade de ministrar aulas teóricas.

Tabela 9. Tempo que os professores de química ministram a disciplina

\begin{tabular}{ccc}
\hline \multicolumn{3}{c}{ Há quanto tempo você ministra esta disciplina? } \\
\hline Menos de $\mathbf{0 1}$ ano & $\mathbf{1 ~ - ~}$ anos & $\mathbf{3}$ - $\mathbf{\text { anos }}$ \\
\hline 0 & 3 & 1 \\
$0 \%$ & $15,78 \%$ & $5,26 \%$ \\
\hline $\mathbf{5}$ - $\mathbf{1 0}$ anos & Mais de $\mathbf{1 0}$ anos \\
\hline 7 & 8 \\
$36,84 \%$ & $42,10 \%$ \\
\hline
\end{tabular}

Tabela 10. Opinião dos professores quanto à dificuldade de ministrar aulas teóricas

\begin{tabular}{ccc}
\hline \multicolumn{3}{c}{ Você possui dificuldade em ministrar as aulas teóricas? } \\
\hline Sim & Não & Um Pouco \\
\hline 0 & 14 & 4 \\
$0 \%$ & $78,95 \%$ & $21,05 \%$ \\
\hline
\end{tabular}

A Tabela 10 expõe $21,05 \%$ dos professores com dificuldade em ministrar aulas teóricas, 0 professor deveria ter total domínio em suas aulas e não possuir dificuldades, principalmente por ser a referência principal do conhecimento em Química na sala de aula. Como todos os professores possuem formação em suas respectivas áreas de atuação, não há justificativa para haver dificuldades em ensinar e promover aulas contextualizadas e dinâmicas que permitam aos alunos desenvolverem aptidão pelo conhecimento Químico. Segundo Lev Vygotsky o desenvolvimento do indivíduo e a aquisição de conhecimentos é resultado da interação do sujeito com o meio, e o professor faz parte desse meio; como fruto dessas trocas e interações, o cérebro tem a capacidade de criar novos conhecimentos. ${ }^{17}$

\subsection{Laboratórios das escolas}

A investigação sobre aulas experimentais também foi realizada, a Tabela 11 mostra a quantidade de laboratórios nas escolas.

Tabela 11. Existência de laboratórios de química nas escolas em que ministra aulas

\begin{tabular}{cc}
\hline A escola na qual você ministra a disciplina possui laboratório de química? \\
\hline Sim & Não \\
\hline 10 & 9 \\
$52,63 \%$ & $47,37 \%$ \\
\hline
\end{tabular}


A Tabela 11 exibe 47,37\% das escolas sem laboratório de química. Os laboratórios de química são essenciais, pois garantem a melhor aprendizagem, os alunos poderiam vivenciar na pratica o que foi ensinado nas aulas teóricas. Devido à complexidade do conteúdo de química, se faz necessário a existência de laboratórios em todas as escolas, os quais despertariam maior interesse por parte dos alunos, promovendo o aprendizado, o que facilitaria a concretização da teoria abstrata discutida em sala de aula. ${ }^{18}$

Visto a quantidade de laboratórios insuficiente, as escolas também não apresentam infraestrutura mínima para o desenvolvimento de aulas experimentais no laboratório. A Tabela 12 relaciona a infraestrutura das escolas com os laboratórios.

Tabela 12. Os laboratórios de química com infraestrutura adequada para aulas experimentais

\begin{tabular}{cc}
\hline \multicolumn{2}{c}{$\begin{array}{c}\text { Se houver laboratório, este possui infraestrutura adequada (logística, segurança e } \\
\text { matéria prima)? }\end{array}$} \\
\hline Sim & Não \\
\hline 3 & 7 \\
$30,00 \%$ & $70,00 \%$ \\
\hline
\end{tabular}

A Tabela 12 mostra a maioria dos laboratórios nas escolas com infraestrutura inadequada (70\%). A infraestrutura adequada consiste de requisitos mínimos de segurança e materiais necessários para a realização de aula experimental, visto que a química específica basicamente transformações, interações e mudanças de comportamentos moleculares, e a experimentação auxilia na epistemologia, principalmente no que tange à problematização e contextualização dos fenômenos químicos.

A falta de estrutura adequada para a realização de determinadas experiências, propõe que os professores realizem experimentos a partir de materiais de baixo custo e/ou improvisados. Essas experiências incidem em uma alternativa talvez eficaz, porém diminui o rendimento das aulas para um ensino qualidade. ${ }^{19}$

Além de toda a infraestrutura, os alunos precisam de conhecimento prévio sobre o tema para realizarem aulas experimentais, com intensivo diálogo e reflexão para possibilitar o acompanhamento e a avaliação dos alunos ao longo do processo experimental. Nesse aspecto, o desenvolvimento de conhecimentos prévios e a problematização das atividades possibilita ao aluno alcançar o processo reflexivo, sendo necessária a proposição de atividades interdisciplinares, contextualizadas e relacionadas ao cotidiano. ${ }^{20} \mathrm{~A}$ Tabela 13 se refere a dificuldade dos professores em ministrar as aulas experimentais.

\subsection{Aulas experimentais}

A Tabela 13 apresenta $42,09 \%$ dos entrevistados com dificuldade em executar as atividades experimentais, o que não deveria acontecer, visto que durante a graduação em química são ministradas diversas aulas experimentais, e com essa vivência, os professores teoricamente são capacitados a desenvolver aulas empíricas. Sendo assim, os resultados mostram que os professores têm deficiências na sua formação inicial e que é necessário o melhor desenvolvimento de competências e habilidades na formação inicial e na atualização de metodologias pedagógicas dos professores. ${ }^{21}$ 
Tabela 13. Dificuldade em exercer atividades experimentais

\begin{tabular}{ccc}
\hline \multicolumn{2}{c}{ Você possui dificuldade em executar as atividades experimentais? } \\
\hline Sim & Não & Um Pouco \\
\hline 3 & 11 & 5 \\
$15,78 \%$ & $57,89 \%$ & $26,31 \%$ \\
\hline
\end{tabular}

O professor deve exercer duas funções importantes dentro da ótica construtivista em suas aulas, segundo BORGES (1998), sendo o primeiro como professor tutor, um guia de aprendizagem que assume uma função intermediária entre uma ação e uma atividade desenvolvida pelo aluno; o outro como professor assessor, com a função de questionar, provocar a reflexão e a solução autônoma de problemas que possam surgir na realização de projetos que os alunos proponham realizar nas aulas experimentais. ${ }^{20} \mathrm{~A}$ Tabela 14 se os professores entrevistados executam atividades experimentais extralaboratoriais.

Tabela 14. Atividades experimentais fora do laboratório

\begin{tabular}{cc}
\hline Você executa atividades experimentais que não seja em laboratório? \\
\hline Sim & Não \\
\hline 13 & 6 \\
$68,42 \%$ & $31,58 \%$ \\
\hline
\end{tabular}

O resultado mostra que a maioria dos professores de química executam atividades experimentais sem laboratório $(68,42 \%)$. Portanto, estes exercem "jogo de cintura" para melhorar os processos epistemológicos do ensino, tornando-se importante forma para minimizar os efeitos negativos da falta de estrutura e induzir ao aprendizado. A experimentação no ensino de química é capaz de levar o aluno a compreender os conceitos químicos, considerados por eles como bastante abstratos. Com a escassez de laboratórios elou infraestrutura, as ideias dos professores para repassar aos alunos o ensino dos fenômenos químicos sem o uso do laboratório é de suma importância no ensino da química. ${ }^{20} \mathrm{~A}$ Tabela 15 mostra a relação entre as atividades experimentais e o conteúdo teórico.

Tabela 15. Correlação entre atividades experimentais e o conteúdo teórico.

\begin{tabular}{cc}
\hline As atividades experimentais estão correlacionadas ao conteúdo teórico? \\
\hline Sim & Não \\
\hline 16 & 3 \\
$84,21 \%$ & $15,79 \%$ \\
\hline
\end{tabular}

A Tabela 15 mostra que a grande maioria dos professores contextualizam e relacionam as atividades experimentais ao conteúdo teórico, as atividades experimentais são indispensáveis, pois permitem ao estudante uma compreensão de como a química se constrói e se desenvolve, o estudante precisa presenciar as reações para complementar a 
prática; quanto mais integrada a teoria for da prática, mais sólida se torna a aprendizagem de química, o que aumenta positivamente o domínio que o aluno tem do conteúdo. ${ }^{22}$. A
Tabela 16 apresenta as atividades experimentais através de materiais

Tabela 16. Execução de atividades experimentais utilizando materiais alternativos

\begin{tabular}{cc}
\hline \multicolumn{2}{c}{ Você executa atividades experimentais utilizando materiais alternativos? } \\
\hline Sim & Não \\
\hline 15 & 4 \\
$78,94 \%$ & $21,05 \%$ \\
\hline
\end{tabular}

A Tabela 16 mostra a maioria das atividades experimentais sendo realizadas com materiais alternativos $(78,94 \%)$, o que pode ou não ser producente, pois a falta dos materiais ideais impede que sejam realizados experimentos químicos complexos e essenciais ao ensino de química. A falta dos materiais necessários é explicada pela escassez de recursos nas escolas, os laboratórios são construções caras, com instrumentos sofisticados, reagentes caros e que não podem ser comercializados livremente, o que dificulta o repasse dos recursos requisitados para as aulas experimentais. Assim sendo, necessário que o professor de química use outros materiais para aulas experimentais. ${ }^{18}$ Contudo, a Tabela 17 mostra a existência de cronograma para as aulas experimentais.

Tabela 17. A existência de cronograma para as aulas experimentais

\begin{tabular}{cc}
\hline \multicolumn{2}{c}{ Existe cronograma para as aulas experimentais? } \\
\hline Sim & Não \\
\hline 4 & 15 \\
$21,05 \%$ & $78,94 \%$ \\
\hline
\end{tabular}

A maioria das escolas não apresenta cronograma para aulas práticas $(78,94 \%)$, os cronogramas são importantes para organização das aulas e é utilizado para instituir a ação educativa, por mais que seja importante não existe uma norma que estabeleça que seja feito cronogramas. ${ }^{23}$ 
Tabela 18. Existência de técnico ou professor laboratorista nas escolas

\begin{tabular}{cc}
\hline Se a escola possuir laboratório de Química. Existe técnico ou professor laboratorista na \\
escola?
\end{tabular}

A Tabela 18 mostra que entre as escolas com laboratório de química $80 \%$ inexiste um técnico ou professor laboratorista, estes são primordiais por possuírem um conhecimento especifico e especializado sobre as normas de segurança em laboratório. Não existe norma que obrigue a presença de técnico laboratorista em aula, neste caso o professor de química, sem auxilio, precisa se capacitar sobre os riscos e todas as instruções para ministrar aula experimental, ou seja, ele deve ser professor e técnico laboratorista ao mesmo tempo. ${ }^{18} \mathrm{~A}$ Tabela 19 mostra a opinião dos professores sobre a necessidade aulas experimentais.

Tabela 19. Professores acreditam na necessidade de aulas em laboratório

\begin{tabular}{cc}
\hline Na sua opinião, os alunos necessitam de aulas em laboratório? \\
\hline Sim & Não \\
\hline 17 & 2 \\
$89,47 \%$ & $10,52 \%$ \\
\hline
\end{tabular}

A maioria dos entrevistados destaca a necessidade de aulas experimentais, a opinião dos professores vai de acordo com o que foi visto na discussão da Tabela 10, sobre a importância das aulas experimentais, pois despertam o interesse dos alunos, causando problematizações que contribuem com o aprendizado. $^{20}$

\section{Considerações Finais}

Os professores de química necessitam de aperfeiçoamento e incentivo para a melhoria pedagógica, embora todos os entrevistados possuam licenciatura em sua área de atuação, boa parte desconhece as normas postuladas pelo governo afim de melhorar o ensino do país e ainda apresentam dificuldade em ministrar aulas teóricas e realizar contextualização dos conteúdos.
Os professores deveriam se capacitar e se atualizar sobre pedagogia, psicologia da educação e metodologias de ensino para que possam ser melhores profissionais e participar mais efetivamente nos processos epistemológicos dos alunos. E o investimento na educação seria essencial para que isto aconteça, além da possiblidade de cursos de especialização mais acessíveis aos servidores públicos, bem como reformulações na carga horária dos professores, uma vez que estes se sentem indispostos para procurarem maneiras de se capacitarem.

As escolas de Uberaba apresentaram ausência de laboratórios, ou quando haviam laboratórios estes estavam com infraestrutura inadequada, além da escassez de materiais indispensáveis para as aulas experimentais, o que demonstra a necessidade emergente de investimentos na educação. 


\section{Referências Bibliográficas}

${ }^{1}$ Palácio do Planalto do Brasil. Constituição Federal. Presidência da República 1988, 1.

${ }^{2}$ Saviani, D. Educação Escolar, Currículo e Sociedade: O problema da Base Nacional Comum Curricular. Movimento Revista de Educação 2016, 4, 54. [CrossRef]

${ }^{3}$ Menin, M. S. D. S. Aprendizagem e Desenvolvimento na Teoria de Jean Piaget. Nuances Estudos sobre Educação 2001, 7, 97. [CrossRef]

${ }^{4}$ Frambach, F. D. A.; Andrade, L. A LDBEN, as Políticas de Formação Continuada de Professores e o Pacto Federativo: Desafios, Entraves e Possibilidades. RevistAleph 2019, 27, 33. [CrossRef]

${ }^{5}$ Ricardo, E. C.; Zylbersztjn, A. Os Parâmetros Curriculares Nacionais para as ciências do Ensino Médio: uma análise a partir da visão de seus elaboradores. Investigigação em Ensino de Ciências 2008, 13, 257.

${ }^{6}$ Sena, P. A legislação do Fundeb. Cadernos de Pesquisa 2008, 38, 134. [CrossRef]

${ }^{7}$ Cury, C. R. J. Vinte Anos da Lei de Diretrizes e Bases da Educação Nacional (LDBEN). Jornal de Políticas Educacionais 2018, 10, 3. [CrossRef]

${ }^{8}$ Krawczyk, N. Reflexão sobre alguns desafios do ensino médio no Brasil hoje. Cadernos de Pesquisa 2011, 41, 144. [CrossRef]

${ }^{9}$ Brasil. Base Nacional Comum Curricular. Proposta preliminar. Segunda versão revista 2016. [Link]

${ }^{10}$ Costa, C. Lei de Diretrizes e Bases da Educação Nacional, Lei 9.394/1996.

${ }^{11}$ Dourado, L. F. Avaliação do Plano Nacional de Educação 2001-2009: questões estruturais e conjunturais de uma política. Educação \& Sociedaade 2010, 31, 677. [CrossRef]

${ }^{12}$ Brasil. Diretrizes Curriculares Nacionais Gerais para a Educação Básica.
${ }^{13}$ Miguez, V. de A.; Braga, J. R. M. Estresse, síndrome de Burnout e suas implicações na saúde docente. Revista Thema 2018, 15, 704. [CrossRef]

${ }^{14}$ Saviani, D. A Pós-Graduação em Educação no Brasil: Trajetória, Situação Atual e Perspectivas. Revista Diálogo Educacional 2000, 1, 1. [CrossRef]

15 Todos pela Educação.; Anuário Brasileiro da Educação Básica 2018. Moderna: São Paulo, 2018. [Link]

${ }^{16}$ Souza, C. T., da Silva, C.; Gessinger, R. M.; $2^{\circ}$ Congresso CLABES, Porto Alegre, Brasil, 2012.

17 Diesel, A., Baldez, A.; Martins, S. Os princípios das metodologias ativas de ensino: uma abordagem teórica. Revista Thema 2017, 14, 268. [CrossRef]

${ }^{18}$ Lopez, M. E.; Petronilho, H. S. Recursos Instrucionais Inovadores para o Ensino de Química. Química Nova na Escola 2017, 39, 12. [CrossRef]

${ }^{19}$ Berezuk, P. A.; Inada, P. Avaliação dos laboratórios de ciências e biologia das escolas públicas e particulares de Maringá, Estado do Paraná. Acta Scientiarum Human and Social Sciences 2010, 32, 207. [CrossRef]

${ }^{20}$ de Lima, J. O. G.; Alves, I. M. R. Aulas experimentais para um ensino de Química mais significativo. Revista Brasileira de Ensino Ciência e Tecnologia 2016, 9, 428. [Link]

${ }^{21}$ Lima, S. R.; Batista, E. L. A formação do professor e suas implicações na educação do ser social. Revista HISTEDBR On-line 2016, 68, 261. [CrossRef]

${ }^{22}$ Airton, P. Proposta para Tornar o Ensino de Química mais Atraente. Revista de Química Industrial 2011, 2, 7. [Link]

${ }^{23}$ Batista, E. L.; Lima, M. R. Dermeval Saviani compromisso e luta por uma pedagogia para além do capital. Revista HISTEDBR On-line 2013, 53, 391. [CrossRef] 